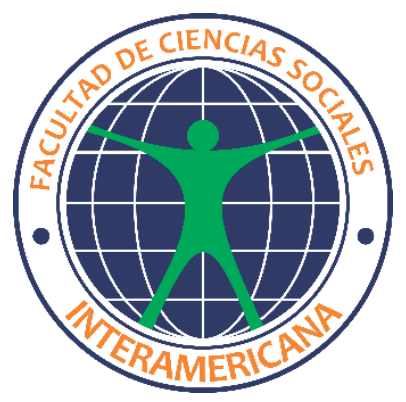

FACULTAD INTERAMERICANA DE CIENCIAS SOCIALES MESTRADO EM CIÊNCIAS DA EDUCAÇÃO

FABRÍCIO ZOUAIN MIRANDA

EDUCAÇÃO CORPORATIVA COMO ESTRATÉGIA DE ENSINO-APRENDIZAGEM E MOTIVAÇÃO NAS ORGANIZAÇÕES 


\section{FABRÍCIO ZOUAIN MIRANDA}

\section{EDUCAÇÃO CORPORATIVA COMO ESTRATÉGIA DE ENSINO-APRENDIZAGEM E MOTIVAÇÃO NAS ORGANIZAÇÕES}

Artigo apresentado como requisito parcial para obtenção do título de Mestre em Ciências da Educação da Facultad Interamericana de Ciencias Sociales.

Orientador : Prof. Doutor Sandro Dau

ASSUNÇÃO, PY 


\title{
EDUCAÇÃO CORPORATIVA COMO ESTRATÉGIA DE ENSINO-APRENDIZAGEM E MOTIVAÇÃO NAS ORGANIZAÇÕES
}

\author{
Fabrício Zouain Miranda ${ }^{1}$
}

\begin{abstract}
Resumo: Este estudo pretende analisar a educação corporativa como estratégia de ensinoaprendizagem e motivação nas organizações Diante deste cenário, delimitou-se como questão de investigação o seguinte problema: $\mathrm{O}$ que fazer para que as empresas percebam o nível de envolvimento de seus funcionários e promovam o desenvolvimento das competências, habilidades, valores organizacionais e culturais, de forma a satisfazer suas necessidades pessoais, profissionais e cumprir seus objetivos empresariais? O objetivo do estudo foi compreender a contribuição da Educação Corporativa, seus efeitos motivacionais nos colaboradores de uma Instituição Financeira Pública e o impacto positivo nos objetivos e resultados empresariais. Faz-se necessário descrever a evolução da Educação Corporativa na formação pessoal e profissional dos colaboradores, explicar a importância da motivação para a retenção de talentos com aumento da competitividade, produtividade e autoestima e reconhecer a necessidade de implantação de uma Universidade Corporativa na formação destes colaboradores, e sua aplicação prática em uma Instituição Financeira Pública. A justificativa está no fato de mostrar que no mundo atual de rápidas mudanças, as organizações estão preocupadas com a formação e capacitação de seus funcionários para que permaneçam sempre motivados e produtivos em seu ambiente de trabalho. Em relação ao tipo de pesquisa, esse estudo foi de cunho bibliográfico, embasado em uma revisão de literatura. Demonstrou-se a partir das conclusões que a capacitação e formação por meio da Educação Corporativa é fator essencial para o sucesso no alcance dos objetivos e resultados das organizações, além de proporcionar enorme satisfação e benefícios ao seu corpo funcional.
\end{abstract}

Palavras chave: Educação. Corporativa. Motivação. Aprendizagem.

\section{INTRODUÇÃO}

No mundo moderno e competitivo em que as empresas enfrentam desafios cada vez maiores com relação ao compromisso, cultura, crença, recrutamento e retenção de seus empregados, estudos múltiplos em diferentes ramos de atividades e em várias empresas indicam que, apesar de muitas vezes apaixonados por seus empregos, os trabalhadores se sentem desmotivados e sobrecarregados nas empresas em que trabalham, por isso, são poucos os que se envolvem com os resultados e o desempenho da organização.

\footnotetext{
1 Graduado em Tecnologia de Processamento de Dados pela Faculdade Capixaba de Informática - FACIN, PósGraduado em Administração Contábil e Financeira e também em Gestão Empresarial pela Centro de Pesquisa e Pós-Graduação da FAESA - Faculdades Integradas Espírito-Santenses, atua como Instrutor Estratégico da Universidade Corporativa CAIXA - Caixa Econômica Federal. E-mail: fabricio.zouain@gmail.com
} 
As organizações que dispõem de universidades corporativas estão gerando um futuro, visto que elas preparam as pessoas para um mercado ininterrupto de mudanças e exercem dois pontos importantes: o tempo de produzir e o tempo de aprender. Isto é, tornou-se real o conceito de que inteligência é um bem indispensável a ser obtida, aplicada e transmitida.

A Educação Corporativa não se resume a salas de aulas, mas a técnicas associativas que criam uma educação continuada, alcançando método intelectual e pessoal da empresa. Dividir experiências, ações e informações, objetivando soluções de problemas, aprender a reaprender, em conjunto com a equipe, torna-se a nova política de Gestão, no qual ainda requisita-se maior escolaridade, mas julga a habilidade e não a aptidão.

Diante deste cenário, delimitou-se como questão de investigação o seguinte problema: O que fazer para que as organizações percebam o nível de envolvimento de seus funcionários e promovam o desenvolvimento das competências, habilidades, valores organizacionais e culturais, de forma a satisfazer suas necessidades pessoais, profissionais e cumprir seus objetivos empresariais?

O objetivo geral do estudo é compreender a contribuição da Educação Corporativa, seus efeitos motivacionais nos colaboradores de uma Instituição Financeira Pública e o impacto positivo nos objetivos empresariais. Entre os objetivos específicos destacam-se: descrever a evolução da Educação Corporativa na formação pessoal e profissional dos colaboradores nas organizações; explicar na estratégia ensino-aprendizagem, a importância da motivação para a retenção de talentos, aumento da competitividade, produtividade e auto estima pessoal e profissional dos colaboradores; reconhecer a necessidade de implantação de uma Universidade Corporativa para o desenvolvimento da Educação Corporativa na formação de seus colaboradores, e sua aplicação prática em uma Instituição Financeira Pública.

A justificativa do estudo está no fato de mostrar que no atual mundo competitivo de grandes e rápidas mudanças, a maioria das organizações empresariais estão muito preocupadas com a formação e capacitação de seus funcionários ao longo de suas carreiras para que permaneçam sempre motivados e produtivos em seu ambiente de trabalho.

Diante disso, a capacitação e formação dos funcionários de uma empresa através da Educação Corporativa é fator essencial para o sucesso no alcance dos objetivos e resultados dessas organizações, além de proporcionar enorme satisfação/benefícios a seu corpo funcional.

\section{FUNDAMENTAÇÃO TEÓRICA}

\subsection{Relação Ensino Aprendizagem e Motivação}


A relação entre ensino e aprendizagem não é mecânica, não é simplesmente a transmissão do professor que ensina e do educando que aprende. Pelo contrário, é uma relação recíproca em que o principal papel do professor nas atividades dos educandos é a de dirigente.

O processo de ensino consiste na resposta planejada às demandas naturais do processo de aprendizagem, portanto, é mais importante para o professor seguir o aprendizado do educando do que se concentrar demais no assunto que está sendo ensinado, ou mesmo em técnicas de ensino como tal.

De acordo com Moreira (1986), os elementos do processo ensino-aprendizagem são compostos por quatro elementos: professor, educando, conteúdo e variáveis ambientais (características da escola), cada um exercendo maior ou menor influência no processo, dependendo de como se relacionam em um dado contexto.

Analisando cada um desses quatro elementos abaixo, é possível identificar as principais variáveis de influência do processo ensino-aprendizagem:

- Educando: habilidade (inteligência, velocidade de aprendizagem); Experiência anterior (conhecimento prévio); Disposição e vontade; Interesse; Estrutura sócio econômica; Felicidades.

- Conteúdo: adequação às dimensões do educando; Significado / valor; Aplicabilidade prática.

- Escola: sistema de crenças dos líderes; Compreender a essência do processo educacional; Liderança.

- Professor: dimensão de relacionamento (relação professor-educando); Dimensão cognitiva aspectos intelectuais e técnico-didáticos); Atitude do educador; Capacidade inovadora; Compromisso com o processo ensino-aprendizagem (Moreira, 1986, p. 34).

Por sua vez, de acordo com Cória-Sabini (2000), a motivação é o conjunto das forças internas que impulsionam o nosso comportamento para objetivos e cuja direção é dada pela nossa inteligência, assim, a motivação para o aprendizado é provavelmente a força dominante, que rege o progresso do educando e capacidade de aprender. A motivação pode ser negativa ou positiva; pode ser tangível ou intangível; pode ser muito sutil e difícil de identificar; ou pode ser óbvia.

Desta forma, as Organizações estão compreensivelmente preocupadas com a motivação. Empregados motivados são felizes, produtivos e leais, e é isso que as empresas buscam. Embora motivar os funcionários seja uma tarefa difícil, considerada por muitos pensadores e estudiosos como um desafio, uma série de teorias sobre motivação no trabalho foram criadas para 
identificar e explicar a motivação das pessoas nos ambientes de negócios e para serem utilizadas como base para o desenvolvimento de práticas, procedimentos e processos nas organizações.

\subsection{A Educação Corporativa e Seus Objetivos}

Somente no final do século XIX que houve uma preocupação com a questão da gestão de pessoas. Na Inglaterra, a partir da Revolução Industrial, pela pressão dos sindicatos e nos EUA, pela organização dos trabalhadores. No caso dos Estados Unidos, com a profissionalização das empresas e a sistematização da gestão de pessoas pela teoria de Taylor da Administração Científica, onde o foco era a produção. Com as máquinas industriais também favorecendo a agricultura, e o desenvolvimento da fábrica, o papel das organizações na sociedade cresce.

Para Meister (1999), existe uma mudança de padrão no tocante ao exercício corporativo, transpondo o modo de ensino e aprendizagem do trabalhador de assistente para articulador do seu conhecimento, onde o ponto do treinamento passa a ser o ajustamento entre a ânsia de conhecimentos a serem assimilados, aplicando os mesmos no trabalho, dando significado a aprendizagem mediante o convívio social e de ações que propiciem a educação continuada dos trabalhadores.

Segundo Baumgartner e Casarini (2012, p. 19),

A associação Brasileira de Educação Corporativa (ABEC), foi criada em 2004, num período de mudanças nos aspectos econômicos internos e consolidações de privatizações, objetivando o estímulo do setor empresarial, por meio das dimensões orgânicas da educação corporativa e de seu valor nas estratégias competitivas do setor produtivo, tendo como fundadoras a Petrobrás, Embratel, Caixa Econômica Federal, Vale, Instituto Albert Einstein, Fundação Unimed, e o Grupo Isvor-Fiat.

Além disto, é um discurso incoerente, apoiado nas habilidades e inteligência, mas requer do colaborador/gestor, a competência de superar o imprevisível, a ação, o exercício associativo e não somente particular (Mundim, 2002).

Moraes (2011, p. 66-67) escreve que:

A Educação corporativa é mais do que treinamento empresarial ou qualificação de mão de obra, é uma prática coordenada de gestão de pessoas e de conhecimentos, tendo como orientação a estratégia de longo prazo de uma organização, onde a validade do conhecimento, cada vez mais, tem prazo reduzido não podendo mais depender das instituições de ensino para desenvolver seus colaboradores. Por esta razão, nasceram as universidades corporativas, com o objetivo de controlar o processo continuado de aprendizagem dos colaboradores.

De acordo com Éboli (2004), na organização taylorista, a mera repetição do trabalho e a produção do conhecimento eram suficientes para um bom resultado nos negócios e a relativa estabilidade do ambiente externo permitia a separação entre a concepção do trabalho e a sua 
realização.

A Educação Corporativa é um processo de educação e aprendizagem e a Universidade Corporativa é a estrutura criada para materializá-la de forma sistêmica, contudo, essas não devem ser vistas como uma ameaça pelas instituições de ensino tradicionais, mas como uma oportunidade de melhoria pessoal e profissional, conforme afirma Éboli (2004).

A Educação Corporativa é uma prática de gestão de pessoas cujo principal objetivo é promover estrategicamente o desenvolvimento dos funcionários, gerenciando conhecimentos, obtendo por consequência, o crescimento da organização.

De acordo com Meister (1999), ao definir um planejamento para educação corporativa, os objetivos devem estar relacionados tendo conhecimento dos problemas reais de instrução, por isso é aconselhável realizar um diagnóstico e análise do problema, seguidos pelos objetivos. As seguintes questões ajudam a este respeito:

- O que se pretende com a educação corporativa na empresa?

- Quem são os educandos e quais são as suas principais características?

- Qual é o comportamento desejado para os colaboradores?

- Qual dificuldade para aprendizagem (estrutura, formação básica, etc.)?

- Quais são os materiais de treinamento e as opções de mídia?

- Quais canais serão usados para educação corporativa? (MEISTER, 1999, p. 35).

Com esses pontos respondidos, é o momento de definir os objetivos do projeto de educação corporativa na empresa. Os responsáveis precisam saber exatamente o que precisa ser feito, mostrando também a mudança que se espera que seja alcançada e, finalmente, desenvolver indicadores que possam servir de base para avaliar se o objetivo foi alcançado ao final do projeto. Portanto, a educação corporativa é um sistema de conhecimento que visa treinar e instruir funcionários de uma empresa com o objetivo de aumentar as chances de sucesso dentro e fora da organização.

Conforme afirma Meister (1999), a "Educação Corporativa pode ser adaptada a diferentes finalidades, portanto, melhorar os resultados e aumentar as chances de sucesso de uma empresa" pode ser traduzido a partir de alguns objetivos, tais como:

- Desenvolver atitudes e comportamentos a serem seguidos;

- Desenvolver habilidades direcionadas ao ramo da empresa;

- Integrar colaboradores com a cultura empresarial;

- Melhorar a produtividade da equipe;

- Aprimorar a gestão do tempo dos funcionários;

- Desenvolver competências de gestão e liderança;

- Instruir os funcionários a operarem adequadamente os equipamentos;

- Ensinar os funcionários a executar procedimentos de forma correta e efetiva;

- Apresentar sistemas e procedimentos de Segurança no Trabalho;

- Qualificar funcionários de forma contínua, com base em mudanças de mercado;

- Demonstrar a totalidade da cadeia de negócios da empresa (MEISTER, 1999, p.

39).

Estes são alguns dos principais objetivos da Educação Corporativa nas empresas, podendo variar de empresa para empresa, uma vez que cada uma tem sua própria especificidade. 


\title{
2.3 Conceitualização da Universidade Corporativa
}

Impulsionada em grande parte pelas complexidades que surgem no desenvolvimento de uma força de trabalho preparada para lidar mudanças nas demandas do mercado e avanços tecnológicos, a Universidade Corporativa surgiu como uma forma das empresas continuarem a ser competitivas ao lidarem com as pressões dos negócios. Assim, o propósito e a estrutura da Universidade Corporativa desenvolveram-se em resposta a essas pressões. O propósito geralmente é modelado em torno do indivíduo e dos desafios da empresa para iniciar ou gerenciar essas mudanças.

Para Goulart (2005, p. 40), a universidade corporativa apresenta a seguinte definição:

\begin{abstract}
Caracterizada como instituição voltada para a educação corporativa permanente, conjugando instalações físicas e portais virtuais, a universidade corporativa tem como desenvolver as competências dos empregados, substituindo a fórmula exclusiva de sala de aula pelas múltiplas formas de aprendizagem. As universidades corporativas atuam desenvolvendo novos formatos e metodologias mais adequadas ao atendimento das necessidades da organização, que possam garantir maior agilidade, flexibilidade e redução de custos. Ao mesmo tempo, promovem a gestão do conhecimento e dos talentos, visando direcioná-lo para a realização das estratégias da organização.
\end{abstract}

Ambos os elementos são conduzidos pela organização patrocinadora que oferece a liberdade de considerar e compensar o clima e a cultura organizacional da empresa. Apesar da variedade nas definições do propósito e estrutura entre as diversas Universidades Corporativas, a maioria dos programas compartilham características comuns que as definem.

De acordo com Éboli (2004), a Universidade Corporativa tem a missão de formar e desenvolver talentos na gestão empresarial, estimular a administração da instrução institucional, por intermédio de recurso do conhecimento ativo e contínuo.

A Universidade Corporativa surge neste novo ambiente de negócios, que requer habilidades mais complexas como solução para enfrentar o desafio de educar os funcionários, clientes, fornecedores e a sociedade, com a finalidade de executar as táticas de negócios da organização. Como pode se observar, a Universidade Corporativa busca conectar teoria e prática, com o objetivo de desenvolver a empresa e o colaborador.

Segundo Meister (1999, p.29), a universidade corporativa é definida como "um guardachuva estratégico para desenvolver e educar funcionários, clientes, fornecedores e comunidade, a fim de cumprir as estratégias empresariais da organização".

Conforme ressalta Meister (1999) e ratificado por Éboli (2004), as Universidades Corporativas não têm necessariamente suas próprias matrizes, com salas de aula ou estrutura 
física, o estudo e a aprendizagem, não precisam estar fixo em um lugar previamente definido, a educação contínua é disponibilizada aos empregados de forma flexível, utilizando diferentes locais, apoios e estruturas, devendo incorporar o crescimento individual e corporativo na melhoria do desempenho da organização.

Macedo (2001, p. 110-111) aponta em seu estudo sobre a Universidade Corporativa da Caixa Econômica Federal, os objetivos e os valores essenciais de uma universidade corporativa:

a) Os objetivos: - promover a gestão do conhecimento e dos talentos, visando direcioná-los para a realização das competências da Caixa; - planejar e estruturar ações e programas de educação que tenham como finalidade a realização dos resultados organizacionais; $\mathrm{e}$ - oferecer instrumentos e ferramentas que incentivem o autodesenvolvimento e a busca de soluções empresariais.

b) Os valores: - A gestão é a principal ferramenta de educação e aprendizagem; - o líder é o principal agente de educação e aprendizagem; - o compartilhamento de conhecimentos e competências é a principal estratégia de aprendizagem para criar uma rede interna e externa de conhecimento; - prover oportunidades de aprendizagem que incentive o autodesenvolvimento e a criação de conhecimento a qualquer hora em todos os lugares; e - a aprendizagem como estratégia para gerar envolvimento e comprometimento incluindo neste processo empregados, clientes, fornecedores e a comunidade.

Definir a Universidade Corporativa requer um olhar sobre a terminologia que a princípio, pode gerar uma expectativa enganosa, pois o termo "Universidade" é problemático.

O primeiro a usar este termo foi Walt Disney na década de 1950. Provavelmente, sua intenção era redefinir a abordagem da própria empresa para o desenvolvimento de funcionários e crescimento corporativo. O termo se espalhou por todo meio corporativo dos Estados Unidos da América com reações diversas.

Do lado positivo, algumas empresas adotaram o termo porque empresta credibilidade. Do lado negativo, algumas empresas se preocupam com as implicações do termo "universidade" e a ansiedade associada ao retorno às instituições tradicionais de ensino superior.

\section{MATERIAIS E MÉTODOS}

Em relação ao tipo de pesquisa, esse estudo foi de cunho bibliográfico, embasado em uma revisão de literatura e pesquisa de campo. Segundo a visão de Oliveira (2007, p. 69) “A pesquisa bibliográfica é uma modalidade de estudo e análise de documentos de domínio científico tais como livros, enciclopédias, periódicos, ensaios críticos, dicionários e artigos científicos".

\section{RESULTADOS}




\subsection{Importância da Educação Corporativa}

Ao implementar a Educação Corporativa em uma empresa, é importante conhecer os principais benefícios que ela oferece. Segundo Meister (1999), o investimento no treinamento para funcionários é extremamente valioso para aumentar a motivação, engajamento e retenção de talentos na empresa, no entanto, vale salientar que estes benefícios podem variar de acordo com o nível e o segmento de atuação da empresa, mesmo assim, alguns benefícios são considerados universais, como por exemplo, o aumento da produtividade.

Para atuar com a Educação Corporativa, a empresa deve elaborar um plano estratégico sobre como desenvolver a educação de seus funcionários buscando a melhor ferramenta avaliando seu custo benefício. Nesse sentido, podemos destacar os Cursos Presenciais e os à Distância. A implementação de um sistema de Educação Corporativa, por sua vez, pode ocorrer pelo menos de 3 maneiras: Cursos Presenciais; Cursos de Educação à Distância (EAD); Híbrido, isto é, parte presencial e parte à distância.

De acordo com Meister (1999, p. 23), são sete as competências necessárias requeridas pelas empresas para delinear as características do empregado ideal:

\footnotetext{
1 Aprendendo a aprender. O funcionário deve ser capaz de fazer perguntas, buscar respostas e aplicar o conhecimento existente a novas situações.

2 Comunicação e Colaboração. Hoje é preciso saber trabalhar em equipe, colaborar com o grupo para compartilhar as melhores práticas negociais e relacionar-se com clientes e fornecedores.

3 Raciocínio criativo e resolução de problemas. Foi-se o tempo em que a direção era a única responsável pela produtividade da empresa. Todos devem contribuir para identificar problemas e apontar soluções.

4 Conhecimento tecnológico. É preciso saber usar, por exemplo, a Intranet e a Internet para pesquisar novos produtos, serviços e ofertas competitivas.

5 Conhecimento de negócios globais. As pessoas precisam conhecer a conjuntura internacional para pensar estratégias de negócios globalizados.

6 Desenvolvimento de liderança. Os funcionários devem ser agentes de mudança em vez de receptores passivos de instruções.

7 Autogerenciamento da carreira. Cabe ao próprio funcionário traçar seu plano de carreira e buscar as qualificações necessárias para a evolução.
}

Portanto, como proceder, se as pessoas não podem ficar estagnadas, mas também não podem dispensar o tempo de suas atividades diárias para realizar treinamento, sob pena, de comprometer os objetivos empresariais estabelecidos.

A Educação Corporativa através do ensino à distância oferece às empresas uma forma de aprendizagem que atende aos pré-requisitos, oferecendo a possibilidade de uma educação flexível, adaptada às necessidades de cada pessoa, que pode ser oferecida a todos os profissionais ao mesmo tempo, em qualquer região que ele esteja, com atualizações constantes, flexibilidade na execução do programa, ampliando a base geográfica do treinamento e, 
sobretudo, melhorando o desempenho dos aprendizes.

Portanto, a Educação Corporativa, muito além de capacitar e qualificar colaboradores para que eles ganhem produtividade e alcancem maiores resultados em suas empresas, é também uma maneira inovadora de incentivar o desenvolvimento e demonstrar que a sua corporação valoriza de fato o crescimento pessoal e profissional de cada pessoa.

\subsection{Objetivo das Universidades Corporativas}

Nos últimos tempos, o crescimento do mercado sem precedentes e a competição global das empresas tornou a Universidade Corporativa uma força motriz por trás da melhoria da vantagem competitiva das organizações.

O crescimento corporativo é, sem dúvida, a principal função de uma Universidade Corporativa, o alinhamento estratégico é um elemento que torna possível esse crescimento. Gerenciamento da Qualidade Total encorajou uma maior relação entre desenvolvimento de recursos humanos, estratégias e práticas comerciais que levam ao crescimento organizacional.

Uma Universidade Corporativa inerentemente relacionada com a missão e objetivos da organização centraliza a aprendizagem na realização do plano estratégico organizacional. Embora ela tenha a capacidade de notar e corrigir os problemas no local de trabalho através do desenvolvimento dos funcionários, também tem a energia para mostrar como essa intervenção se relaciona com o plano estratégico da organização.

Conforme afirma Meister (1999), o Diretor ou Gestor de Aprendizagem exerce um papel crucial para o desenvolvimento da aprendizagem em uma organização, através de uma abordagem universitária corporativa. Ele garante que a alta administração aprove e patrocine a ideia da aprendizagem em cascata para toda a organização.

A Universidade Corporativa adota um currículo integrado que incorpora uma variedade de intervenções de aprendizagem. A aprendizagem não está contida em uma sala de aula de treinamento, mas dispersa em toda a organização através de uma variedade de meios e métodos. A Universidade Corporativa é realmente um guarda-chuva que cobre tudo, desde tutoria e aulas particulares até workshops, aprendizado baseado em computador e aulas da faculdade, segundo Meister (1999).

Bayma (2005, p.28) apresenta uma visão realística sobre o tema ao afirmar que:

A universidade corporativa é um modelo de gestão do desenvolvimento das competências das empresas, por intermédio do desenvolvimento do patrimônio humano. Sua implantação, ao contrário do que muitos imaginam, é complexa. Sua operação requer uma profunda mudança na cultura da organização, sobretudo a gerencial. [...] A partir dessa compreensão é possível, por exemplo, distinguir que um 
número relevante de entidades, autodenominadas universidades corporativas, não passam de um departamento de T\&D com componentes modernos de TI, e não de educação.

Através da abordagem universitária corporativa, as iniciativas de treinamento são baseadas em competências e estrategicamente alinhadas. Esta abordagem expandida permite que os funcionários participem dessas breves explosões de treinamento e / ou por longos períodos de tempo e em cascata por toda a organização, conforme destaca Meister (1999). Esta mudança proporcionou maior liberdade no tempo, lugar e método das oportunidades de aprendizado fornecidas.

\section{DISCUSSÃO}

A Universidade Corporativa é uma ferramenta ideal para gerar a visão coletiva para o futuro, a compreensão dos vários modelos mentais no trabalho e a reflexão sobre a "grande imagem" porque está conectada ao planejamento estratégico. As teorias da aprendizagem de adultos e da aprendizagem organizacional estão intimamente ligadas porque o crescimento corporativo é alcançado através do desenvolvimento individual.

A implementação de todos os objetivos, os componentes, a gestão e o financiamento são definidos pela própria organização. Eles moldam e redefinem as categorias para trabalhar dentro de sua própria cultura e clima organizacional no estabelecimento de uma Universidade Corporativa que alcançará o desempenho organizacional inerente ao seu propósito. Segue-se que as teorias apropriadas também devem ser determinadas pela organização. Desta forma, a definição de Universidade Corporativa tem capturado convincentemente a sua essência.

A Universidade Corporativa pode assumir um processo de pensamento coletivo sobre aprendizagem organizacional e aprendizagem ao longo da vida. O objetivo na fase de implementação é gerar essa atmosfera de aprendizado desencadeada com as energias corporativas. Uma das principais considerações durante a implementação é a promoção. Os métodos de promoção dependem dos recursos disponíveis e da natureza da organização.

\footnotetext{
As práticas de educação corporativa devem favorecer uma atuação profissional impregnada de personalidade, criando condições para o desenvolvimento do conhecimento criador e da postura empreendedora e para o florescimento de líderes eficazes. Cada vez mais se percebe a necessidade de as empresas deixarem de encarar o desenvolvimento de pessoas como algo pontual, treinando-as em habilidades específicas. A postura voltada à aprendizagem contínua e ao autodesenvolvimento é um estado de espírito, um processo de constante crescimento e fortalecimento de indivíduos talentosos e competentes. Cabe às organizações, entretanto, criar um ambiente favorável para sua manifestação (EBOLI, 2004, p. 44).
}

As reuniões locais de pessoal, as mensagens eletrônicas e as reuniões de todos os funcionários são várias maneiras de projetar a missão da universidade corporativa, seu 
propósito, sua estrutura e seu vínculo com a organização. A promoção da Universidade Corporativa é um processo contínuo que pode ocorrer durante os estágios de Avaliação Organizacional, Alinhamento Estratégico e / ou Desenvolvimento Curricular.

O prazo para a implementação é variável, dependendo da rapidez com que a organização deseja promover a ideia e o valor de investimento que será aportado para a promoção. Cada funcionário precisa conhecer e determinar o programa, a trilha ou currículo que melhor se adequa à sua carreira interna. Essa versatilidade fornece um ambiente onde os funcionários estão empenhados na aprendizagem contínua de uma natureza crítica e abrangente.

O objetivo é desenvolver funcionários que estejam mais bem preparados e mais inclinados a contribuir para a mudança no local de trabalho.

Aportar um investimento nesse tipo de aprendizagem é possível, mas talvez não seja uma medida útil na determinação da eficácia organizacional. Uma melhor abordagem pode ser capitalizar o alinhamento estratégico da Universidade Corporativa ao mostrar como o programa abordou o plano estratégico e contribuiu para avanços na produção, aumento nas inovações, redução de tempo e erros, etc.

A avaliação da Universidade Corporativa é um componente significativo, que exige maior ênfase. Medir o retorno financeiro sobre o investimento em capital humano é um fator crítico no desenvolvimento e gerenciamento de uma Universidade Corporativa, pois é um esforço caro. As formas de medir o retorno desses custos devem ser examinadas e avaliadas, por isso, tamanha é a insatisfação na cultura de uma organização, é difícil isolar o impacto da Universidade Corporativa. Embora os métodos e processos atuais para avaliação e as análises do Custo / Benefício, fornecem bases úteis, os métodos de avaliação e as técnicas específicas para a Universidade Corporativa devem ser exploradas.

As Universidades Corporativas surgiram para facilitar ainda mais o processo de Educação nas empresas, pois aliadas à tecnologia, trazem mais agilidade e possibilidade de atualização constante já que se utilizam, dentre outros, o ensino à distância, onde se dispensa gastos com salas de aula e professores. Para ilustrar esta nova tendência tem-se um número impressionante (FERREIRA, 2010, p. 9).

A implantação da Universidade Corporativa CAIXA, a partir de 2001 permitiu uma atuação mais efetiva em relação ao crescimento de habilidades individuais e coletivas, além de ampliar o processo para parceiros como os Lotéricos, Órgãos do Governo, Prefeituras Municipais, entre outros, representando um importante passo no processo evolutivo da educação corporativa da Empresa (CAIXA [b], 2018).

Schlemm (2005, p. 86) considera que a Educação Corporativa tem como principal papel, 
“a criação da cultura própria e necessária para que uma organização específica desenvolva os valores e hábitos de conduta mais coerentes com o tipo de atividade e tecnologia utilizadas no empreendimento".

A Gestão de Aprendizagem na Universidade Corporativa CAIXA é exercida pela Gerência Nacional de Educação Corporativa, que responde pelos processos de estruturação e implantação da educação corporativa da empresa, os quais se concretizam em ações educacionais organizadas em módulos, cursos e programas de aprendizagem, se reportando diretamente à alta Administração (CAIXA [b], 2018).

A Educação Corporativa na CAIXA é orientada por uma proposta pedagógica própria, elaborada em função do perfil de profissional que a empresa deseja ter em seus quadros: mentes críticas, criativas e capazes de estabelecer paralelos entre o conhecimento e a prática vigente na empresa. A CAIXA mantém seu objetivo de conseguir abranger, no mais breve tempo, todos aqueles que têm contato com ela, com os seus produtos e serviços e / ou que procuram nela formas de parcerias de desenvolvimento (CAIXA [b], 2018).

Para a Universidade Caixa, o desenvolvimento das pessoas é um processo contínuo em que todos os vínculos essenciais da CAIXA, seus empregados, clientes, fornecedores, parceiros, desenvolvem uma visão compartilhada sobre a CAIXA, sua missão, seus valores e sua importância junto à sociedade (CAIXA [c], 2018).

Neste contexto partiu-se da premissa sobre a redução gradativa do conhecimento como fator de perda de competitividade e implicação direta nos negócios da empresa. Como resposta a esta afirmação, encontrou-se na bibliografia apresentada, informações coerentes com a atual realidade e com a frenética urgência das mudanças, voltadas para um novo padrão de gestão onde o investimento no capital humano, se traduz no aumento de bens intangíveis e de difícil mensuração (CAIXA [a], 2018).

Portanto, para que estas empresas se mantenham competitivas e flexíveis diante das novas regras impostas pelo mercado, necessitam formar e capacitar seu corpo funcional, mediante estratégias previamente definidas, criando estruturas educativas alinhadas a elas, como forma de elevar o nível de conhecimento e habilidades de seus colaboradores.

\section{CONCLUSÃO}

As conclusões finais do estudo mostraram que a Educação Corporativa emergiu no interior da Caixa Econômica Federal como substituta intransigente aos modelos de treinamento e desenvolvimento tradicionais e à educação presencial, e passa a ser virtual e disponível a 
qualquer tempo e em qualquer lugar. Isso pode ser visto através da resposta dos entrevistados, no qual a grande maioria considera que as ações Educacionais promovidas através da Universidade Corporativa estão alinhadas ao planejamento estratégico da empresa.

Percebeu-se que Universidade Corporativa Caixa promove as parcerias internas com seus líderes e gestores envolvendo-os e comprometendo-os e responsabilizando-os pelo processo de aprendizagem de suas equipes, estimulando a participação nos programas educacionais e criando um ambiente de trabalho propício à aprendizagem, disponibiliza um portal na web para acesso de todos os empregados, estagiários e adolescentes aprendizes tanto na Intranet quanto na Internet, vinte e quatro horas por dia, sete dias na semana, cujos recursos e funcionalidades podem ser destacados em diversos ambientes virtuais, além de um campus físico onde acontecem cursos presenciais.

Constatou-se que a Universidade Corporativa Caixa está voltada para uma educação inclusiva, mantendo canais de comunicação abertos ao público interno e externo, num modelo de gestão que estimula o compartilhamento de conhecimentos organizacionais e a troca de experiências, integra o sistema de educação com o modelo de administração da percepção e cria mecanismos de gestão que favorecem a construção social do conhecimento.

Foi possível ainda que as ações pedagógicas e o treinamento recebido promovem resultados positivos na organização e na qualificação profissional dos seus colaboradores, melhorando significativamente o desempenho dos funcionários no ambiente de trabalho.

Por fim, considera-se que a aprendizagem obtida nas Ações Educacionais através da Universidade Corporativa influencia na melhoria dos resultados da empresa e na qualidade de vida dos empregados. Destaca-se que a alta direção da CAIXA está diretamente envolvida e comprometida com o sistema de Educação Corporativa através da Gerência Nacional de Educação Corporativa, responsável por promover à geração, a assimilação, a difusão e a aplicação de conhecimentos neste âmbito ao implantar o padrão de administração de pessoas por aptidão e conceber ações e programas educacionais alinhados às estratégias da Caixa.

Outro ponto relevante é o fato de que a CAIXA, através das estratégias aplicadas, tem investido na sustentabilidade da empresa ao promover a capacitação de seus colaboradores, refletindo no aumento da qualidade de seus produtos, serviços e negócios. Para isso, desenvolve mecanismos para melhoria do relacionamento interno e externo, sejam através de ações educacionais como os programas Adolescente Aprendiz, PróUni e Estágios de nível médio e superior e na garantia dos direitos trabalhistas, sindicais de seus colaboradores, no respeito à diversidade e a equidade. 
Por fim, é importante frisar que o objetivo do estudo foi alcançado na medida em que compreendeu a contribuição da Educação Corporativa por meio da Universidade Corporativa, por outro lado, mostrou que seus efeitos motivacionais nos colaboradores são considerados de grande valia para a realização dos resultados alcançados.

\section{REFERÊNCIAS}

BAUMGARTNER, Marcos; CASARINI, Fabiana Gradela. Educação Corporativa da teoria à prática. São Paulo: Editora Senac, 2012.

BAYMA, Fátima. Educação à Distância e Educação Corporativa. In BAYMA, Fátima (org). Educação Corporativa: desenvolvendo e gerenciando competências. São Paulo: Pearson Prentice Hall, 2005.

BERGAMINI, C. Motivação nas Organizações. 4. ed. São Paulo: Atlas, 1997.

CAIXA [a]. Informações Financeiras. Caixa Econômica Federal. Disponível em: http://www.caixa.gov.br/sobre-a-caixa/informacoes-financeiras/Paginas/default.aspx. Acesso em 25 de Julho de 2018.

CAIXA [b]. Educação Corporativa. Caixa Econômica Federal. Disponível em http://www.fnq.org.br/informe-se/artigos-e-entrevistas/cases-de-sucesso/caixa-promoveeducacao-corporativa-para-seus-colaboradores. Acesso em 3 de julho de 2018.

CAIXA [c]. Universidade Corporativa Caixa. Caixa Econômica Federal. Disponível em https://universidade.caixa.gov.br/. Acesso em 3 de julho de 2018.

CAMPOS, Dinah Martins de Souza. Psicologia da aprendizagem. Petrópolis, Vozes, 1986.

CÔRIA-SABINI, Maria Aparecida. Fundamentos da Psicologia Educacional. Editora Ática - $4^{\text {a }}$ ed, São Paulo, 2000.

DAU, Sandro, DAU Shirley. Ciência: Pesquisa, Métodos e Normas. Minas Gerais, Expresso Gráfica, 2013

ÉBOLI, Marisa. A importância da educação setorial na capacitação empresarial. In: Instituto Euvaldo Lodi. Capacitação Empresarial. Brasília: IEL/NC/SEBRAE/NA, 2005.

ÉBOLI, Marisa P. Educação Corporativa no Brasil: Mitos e Verdades. São Paulo: Editora Gente - 2004.

FERREIRA, Patrícia Genehr. A percepção dos empregados da Caixa Econômica Federal quanto à Universidade Caixa (UC): um estudo na Região metropolitana de porto alegre. Universidade Federal Do Rio Grande Do Sul. Escola de administração. Departamento de ciências administrativas. Porto Alegre, 2010.

GAGNÉ, R. Como se realiza a aprendizagem. Rio de Janeiro: Livro Técnico, 1971; 
FERREIRA, Patrícia Genehr. A percepção dos empregados da Caixa Econômica Federal quanto à Universidade Caixa (UC): um estudo na Região metropolitana de porto alegre. Universidade Federal Do Rio Grande Do Sul. Escola de administração. Departamento de ciências administrativas. Porto Alegre, 2010.

MACEDO, Ricardo B. Universidades corporativas: proposição de um modelo conceitual. Dissertação (Mestrado) - Fundação Getúlio Vargas, Brasília, 2001.

MEISTER, J.C. Educação Corporativa: a gestão do capital intelectual através das universidades corporativas. São Paulo: Makron Brooks, 1999;

MOREIRA, D. A. Elementos para um plano de melhoria do ensino universitário ao nível de instituição. Revista IMES, São Caetano do Sul - ano III, 1986;

MORAES, Márcia Vilma Gonçalves de. Treinamento e desenvolvimento: educação corporativa: para as áreas de saúde, segurança do trabalho e recursos humanos. $1^{\text {a }}$ Ed. São Paulo: Érica, 2011.

MUNDIM, Ana Paula Freitas. Desenvolvimento de produtos e educação Corporativa. 1.ed. São Paulo: Atlas, 2002.

OLIVEIRA, Djalma de Pinho Rebouças de. Planejamento Estratégico: conceitos, metodologia e práticas- 23ª Ed. São Paulo: Atlas, 2007.

SCHLEMM, Marcos Mueller. Reflexos e considerações sobre a educação corporativa. In: Instituto Evaldo Lodi. Capacitação Empresarial. Brasília: IEL/NC/SEBRAE/NA, 2005. 